\title{
Recent Advances in the Physicochemical Properties and Biotechnological Application of Vitreoscilla Hemoglobin
}

\author{
Fei Yu ${ }^{1,2}$, Xinrui Zhao ${ }^{1,2, *}$, Ziwei Wang ${ }^{1} \mathbb{D}$, Luyao Liu ${ }^{1}$, Lingfeng Yi ${ }^{1}$, Jingwen Zhou ${ }^{1,2}$, Jianghua Li ${ }^{1,2}$, \\ Jian Chen ${ }^{1,2}$ and Guocheng Du ${ }^{1,2,3, *}$
}

1 Key Laboratory of Industrial Biotechnology, Ministry of Education, School of Biotechnology, Jiangnan University, 1800 Lihu Road, Wuxi 214122, China; 7190201070@stu.jiangnan.edu.cn (F.Y.); 1022180104@stu.jiangnan.edu.cn (Z.W.); 1024180215@stu.jiangnan.edu.cn (L.L.); 1023180116@stu.jiangnan.edu.cn (L.Y.); zhoujw1982@jiangnan.edu.cn (J.Z.); lijianghua@jiangnan.edu.cn (J.L.); jchen@jiangnan.edu.cn (J.C.)

2 Science Center for Future Foods, Jiangnan University, 1800 Lihu Road, Wuxi 214122, China

3 Key Laboratory of Carbohydrate Chemistry and Biotechnology, Ministry of Education, Jiangnan University, 1800 Lihu Road, Wuxi 214122, China

* Correspondence: zhaoxinrui@jiangnan.edu.cn (X.Z.); gcdu@jiangnan.edu.cn (G.D.)

check for updates

Citation: Yu, F.; Zhao, X.; Wang, Z.; Liu, L.; Yi, L.; Zhou, J.; Li, J.; Chen, J.; Du, G. Recent Advances in the Physicochemical Properties and Biotechnological Application of Vitreoscilla Hemoglobin. Microorganisms 2021, 9, 1455. https://doi.org/10.3390/ microorganisms 9071455

Academic Editor: Benjamin C. Stark

Received: 27 June 2021

Accepted: 4 July 2021

Published: 7 July 2021

Publisher's Note: MDPI stays neutral with regard to jurisdictional claims in published maps and institutional affiliations.

Copyright: (C) 2021 by the authors Licensee MDPI, Basel, Switzerland. This article is an open access article distributed under the terms and conditions of the Creative Commons Attribution (CC BY) license (https:/ / creativecommons.org/licenses/by/ $4.0 /)$.

\begin{abstract}
Vitreoscilla hemoglobin ( $\mathrm{VHb})$, the first discovered bacterial hemoglobin, is a soluble hemebinding protein with a faster rate of oxygen dissociation. Since it can enhance cell growth, product synthesis and stress tolerance, $\mathrm{VHb}$ has been widely applied in the field of metabolic engineering for microorganisms, plants, and animals. Especially under oxygen-limited conditions, $\mathrm{VHb}$ can interact with terminal oxidase to deliver enough oxygen to achieve high-cell-density fermentation. In recent years, with the development of bioinformatics and synthetic biology, several novel physicochemical properties and metabolic regulatory effects of $\mathrm{VHb}$ have been discovered and numerous strategies have been utilized to enhance the expression level of $\mathrm{VHb}$ in various hosts, which greatly promotes its applications in biotechnology. Thus, in this review, the new information regarding structure, function and expressional tactics for $\mathrm{VHb}$ is summarized to understand its latest applications and pave a new way for the future improvement of biosynthesis for other products.
\end{abstract}

Keywords: Vitreoscilla hemoglobin; high-cell-density fermentation; physicochemical properties; metabolic regulation; expressional tactics; applications

\section{Introduction}

Vitreoscilla hemoglobin $(\mathrm{VHb})$ is the first bacterial hemoglobin discovered in gramnegative bacterium Vitreoscilla sp. C1 [1]. Vitreoscilla was found in oxygen-limited conditions like stagnant ponds and decaying vegetable matter [2,3], but it is strictly aerobic based on the special $\mathrm{VHb}$ to adapt to hypoxic conditions. $\mathrm{VHb}$ was originally named "cytochrome $o$ (Суо)" because of some similar properties with cytochromes [4,5]. Subsequently, the amino acid sequencing of "Cyo" was completed and showed that it had a high homology with eukaryotic hemoglobins [2].

$\mathrm{VHb}$ is a single-domain hemoglobin $(\mathrm{SDHb})$ that is different from the two other two kinds of bacterial hemoglobins, FHbs (flavohemoglobins, a VHb-like globin fused with flavin-binding domain) and trHbs (truncated hemoglobins, a single-domain hemoglobin approximately $20 \%$ smaller than $\mathrm{SDHb}$ ) [6]. Based on the unique structure of $\mathrm{VHb}$, it can efficiently bind and transport oxygen to the respiratory chain by interacting with terminal oxidase, especially under oxygen-limited conditions [6]. In addition, VHb also can interact with transcriptional regulators responsible for oxygen response, triggering oxidative phosphorylation in the cells [6].

Based on its powerful oxygen transport capacity, $\mathrm{VHb}$ has been widely applied in the field of metabolic engineering for microorganisms, plants and animals. By enhancing the 
regeneration of ATP and $\mathrm{NAD}^{+}$and improving the activity of the TCA cycle $[7,8], \mathrm{VHb}$ can be used to promote the growth of microbial, plant and animal cells [7,9], improve the synthesis of target products under oxygen-limited conditions [10], and increase the effect of microorganisms on bioremediation [11].

In recent years, with the development of bioinformatics and synthetic biology, several novel physicochemical properties and functions of $\mathrm{VHb}$ were discovered and numerous strategies were utilized to enhance the expression level of $\mathrm{VHb}$ in various hosts, resulting in its wide application in biotechnology. Therefore, in this review, the information of structure and functions for $\mathrm{VHb}$ are summarized to make $\mathrm{VHb}$ become a promising and practical tool in metabolic engineering.

\section{Biochemical Function of $\mathbf{V H b}$}

\subsection{The Oxygen-Binding Property of $\mathrm{VHb}$}

$\mathrm{VHb}$ is a homodimer composed of two identical subunits (146 amino acids for each subunit) and two molecules of $b$-type heme. In the early studies, $\mathrm{VHb}$ was considered as a cytochrome $o$ [1]. Subsequently, researchers gradually recognized that $\mathrm{VHb}$ is a kind of hemoglobin based on its primary structure, spectral properties, and oxygen binding kinetics [2]. Under different environmental conditions, $\mathrm{VHb}$ can present in three different states: oxidized state, reduced state, and oxygenated state. When the iron atom in the heme of $\mathrm{VHb}$ is in the ferrous state, it presents in a reduced state and can reversibly combine with the oxygen. The oxygenated state is the transition state between the reduced state and oxidized state and is also the most important stable state that participates in oxygen related metabolic pathways and improves the efficiency of oxidative phosphorylation in the respiratory cells $[12,13]$.

Compared with other eukaryotic hemoglobins, the rate constant of $\mathrm{VHb}$ binding to oxygen $\left(k_{\text {on }}=78 \mu \mathrm{M}^{-1} \mathrm{~s}^{-1}\right)$ is in the average level, but the dissociation rate constant of $\mathrm{VHb}$ and oxygen $\left(k_{\text {off }}=5000 \mathrm{~s}^{-1}\right)$ is hundreds of times higher, meaning $\mathrm{VHb}$ is apt to release a large amount of oxygen [13]. In Vitreoscilla and Escherichia coli, the cellular VHb localizes in the periplasmic space and close to cell membrane, which facilitates it functioning as a respirator to transport oxygen to the cell membrane under hypoxic conditions [14]. Whereas in yeast, it was confirmed by two-hybrid experiments that $\mathrm{VHb}$ can interact with subunit I of cytochrome bo ubiquinol oxidase and enhance its activity [15].

\subsection{The Activity of Terminal Oxidase and Peroxidase}

On the one hand, as early as thirty years ago, it has been verified that $\mathrm{VHb}$ has terminal oxidase activity. After the vgb gene (Vitreoscilla hemoglobin gene) was transformed, under the condition of succinate or lactate for substrates, the E. coli mutant that lacks cytochrome $o$ and $d$ terminal oxidases could perform aerobic respiration and grow normally [16]. On the other hand, the activity of peroxidase was detected for $\mathrm{VHb}$ through in vitro experiments, and many factors ( $\mathrm{pH}$, temperature, etc.) can affect its activity $[17,18]$. In the following, in order to enhance the peroxidase activity of $\mathrm{VHb}$ for the application in biomedicine and dye decolorization, several mutated $\mathrm{VHb}$ that presenting high peroxidase activity under specific $\mathrm{pH}$ conditions were obtained [19]. Based on these mutants of $\mathrm{VHb}$, it was found that the conserved amino acid residues 53 and 54 (glutamine and proline) in the distal pocket of $\mathrm{VHb}$ are closely related to its peroxide activity. Aiming for these two key catalytic sites, more and more designed mutants (P54R or Q53H/P54C) with higher peroxidase activity were obtained by site-directed mutations [20,21].

\subsection{The Potential Sulfide Receptor and Storage}

Different from the classic $\mathrm{H}_{2} \mathrm{~S}$-binding monomeric hemoglobin from Lucina pectinate [22], $\mathrm{VHb}$ exhibits unusual characteristics in its reactivity with $\mathrm{H}_{2} \mathrm{~S}$, such as steric constraints at position E11 (Leu), that play important roles in regulating the binding stability of $\mathrm{H}_{2} \mathrm{~S}$ and $\mathrm{VHb}$. The kinetic parameters for interaction between $\mathrm{VHb}$ and $\mathrm{H}_{2} \mathrm{~S}$ were determined by UV-visible spectroscopic analysis and Resonance Raman (RR) spectroscopic 
analysis $\left(K_{o n}=1.2 \times 10^{5} \mathrm{M}^{-1} \mathrm{~S}^{-1}\right.$ and $\left.K_{\text {off }}=2.5 \times 10^{-4} \mathrm{~S}^{-1}\right)$, indicating that $\mathrm{VHb}$ serves as a potential sulfide receptor and has a storage function in the cells [23].

\subsection{Other Functions}

Besides the functions mentioned above, $\mathrm{VHb}$ also has the properties of lipid binding. $\mathrm{VHb}$ not only can interact with the monolayers formed by natural phospholipids but also reversibly binds to free fatty acids [24]. Since the binding site is located in the distal pocket of the heme, combination with lipids may affect the oxygen affinity of $\mathrm{VHb}$ and its physiological functions [24]. In addition, $\mathrm{VHb}$ can also interact with other intracellular enzymes or transcriptional regulators to increase their activities or activate the downstream metabolic pathways (Table 1).

Table 1. Interactions between $\mathrm{VHb}$ and intracellular enzymes or regulators.

\begin{tabular}{lcc}
\hline \multicolumn{1}{c}{ Enzymes/Regulators } & Functions & References \\
\hline Flavoreductase & Relieve nitrosative stress & {$[25]$} \\
Transcriptional regulators (OxyR, Fnr, ArcA, Crp) & Transcriptional regulation & {$[26]$} \\
2,4-dinitrotoluene dioxygenase & Enhance dioxygenase activity & {$[27]$} \\
\hline $\begin{array}{l}\text { OxyR: oxidative stress regulator; Fnr: fumarate and nitrate reductase; ArcA: aerobic respiration control A; Crp: } \\
\text { catabolic repressor protein. }\end{array}$
\end{tabular}

\section{Structure and Bioinformatics Analysis of $\mathrm{VHb}$ and Its Mutants}

\subsection{The Structure of VHb and Its Mutants}

Based on the analysis of crystal structure, $\mathrm{VHb}$ forms six $\alpha$-helix regions (A, B, E, F, G and $\mathrm{H}$ ), which is different from other eukaryotic hemoglobins with eight $\alpha$-helix regions ( $\mathrm{A}$, $\mathrm{B}, \mathrm{C}, \mathrm{D}, \mathrm{E}, \mathrm{F}, \mathrm{G}$ and $\mathrm{H})$, and has a unique distal heme pocket [28]. In addition, there are four residues (TyrB10, GlnE7, ProE8 and LeuE11) that are closely related to the oxygen-binding property [29]. Notably, unlike most eukaryotic hemoglobins, the distal His (E7) residue in $\mathrm{VHb}$ is substituted by Gln residue, which cannot form hydrogen bonds with oxygen [30]. Furthermore, the Gln (E7) residue in VHb is responsible for the disorder of the D-helix region that forms between the polypeptide segment from Phe-43 (CD1) to Leu-57 (E11), leading to the weaker affinity to oxygen, higher oxygen dissociation constant $\left(K_{\text {off }}\right)$ and rapid rate of oxygen transfer [30].

Apart from the wild-type $\mathrm{VHb}$, the effect of key amino acid residues on the structure and function of $\mathrm{VHb}$ mutants was studied through site-directed mutagenesis. At first, the Tyr-29 (B10) played an important role in maintaining the stability of oxygen binding [31]. Next, the structure of the TyrB10Phe mutant is almost indistinguishable from the wild type, and the structure related to D-region ordering and E7 chain of the TyrB10Ala mutant is significantly different from the wild type [31]. Moreover, $\mathrm{VHb}$ also had a unique proximal heme pocket, with the structure being formed by a hydrogen-bonding network consisting of HisF8-TyrG5-GluH23 and TyrG5-TyrH12 [32]. In addition, the TyrG5Phe and TyrG5Leu mutants cannot form a stable oxygenated state and do not exhibit any nitric oxide dioxygenase activity [32]. However, the TyrH12Phe and TyrH12Leu mutants showed little effect on the oxygen-binding capacity, which is inconsistent with the previous predicted results that TyrH12Leu mutation could enhance oxygen diffusion and accumulation [32].

\subsection{The Homology Analysis of $\mathrm{VHb}$}

It has been reported that $\mathrm{VHb}$ has a lower homology with eukaryotic hemoglobins and the highest homology only can reach $24 \%$ (leghemoglobin from Lupinus luteus). However, after the alignment of amino acid sequence between $\mathrm{VHb}$ and prokaryotic proteins, eight categories of bacterial homologous proteins were found, including bacitracin resistance protein BacA, hemoglobins $(\mathrm{Hb})$, hypothetical protein $(\mathrm{HP})$, NO-inducible flavohemoprotein (NOIFHP), flavohemoprotein (FHP), cytochrome $o$ (Cyo), nitric oxide dioxygenase (NOD) and dihydropteridine reductase (DHPR). 
Among eight homologous categories, the proteins with highest homology with $\mathrm{VHb}$ were selected, including BacA from Clostridium paraputrificum (WP_027099064.1, 73.05\%), $\mathrm{Hb}$ from Clostridium sp. CAG:221 (CDB15533.1, 71.63\%), HP from Intestinibacter bartlettii DORA_8_9 (ETI93048.1,68.79\%), NOIFHP from Ureibacillus sp. Re31 (WP_191706693.1, 66.67\%), FHP from Lysinibacillus sphaericus C3-41 (ACA41869.1, 65.97\%), Cyo from Clostridium sp. (SCK00776.1, 65.73\%), NOD from Caryophanon latum (WP_066464548.1, 65.28\%), and DHPR from Bacilli bacterium VT-13-104 (KKE77556.1, 59.86\%) (Figure 1).
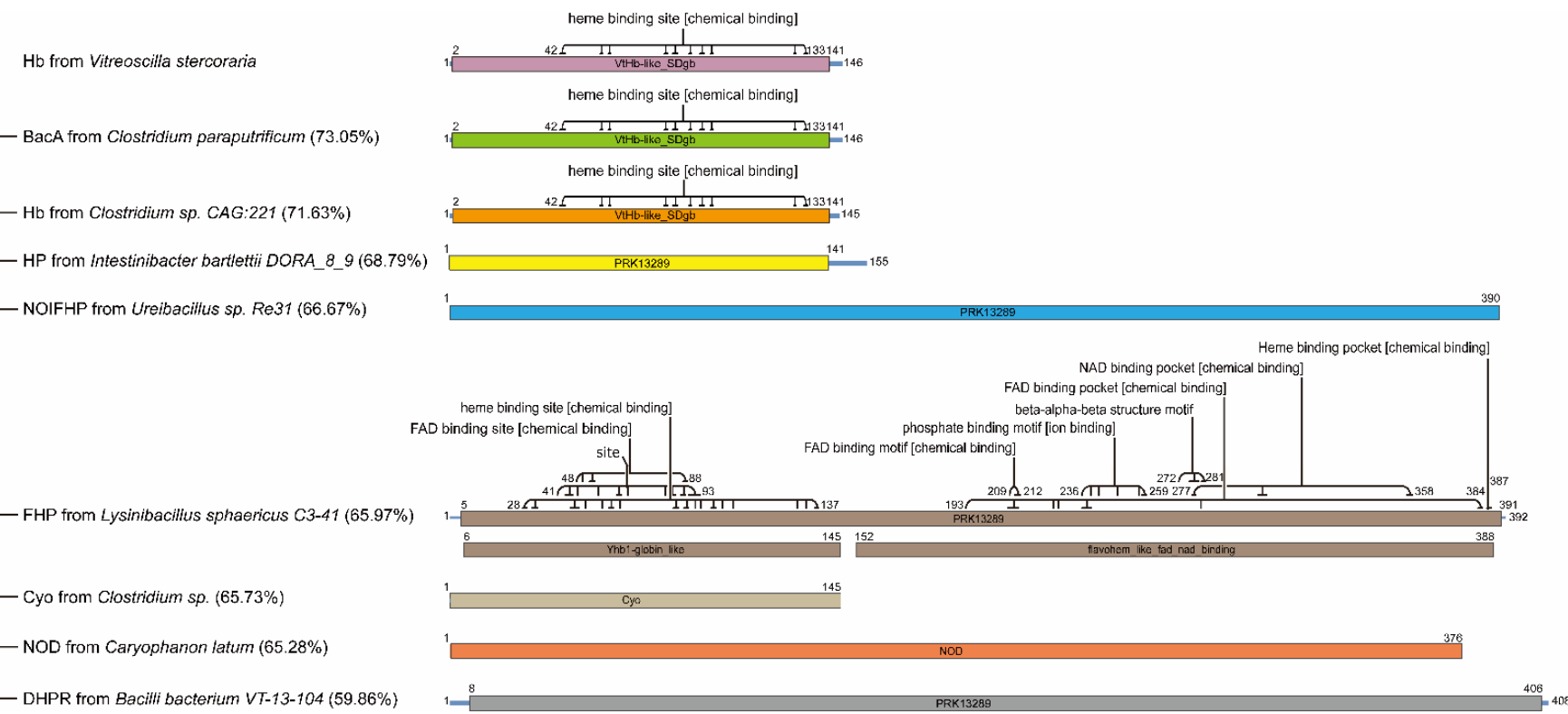

Figure 1. The homology analysis of $\mathrm{VHb}$. The accession numbers in GenBank of eight homologous proteins and their homology with VHb: BacA from C. paraputrificum (WP_027099064.1, 73.05\%), Hb from Clostridium sp. CAG:221 (CDB15533.1, 71.63\%), HP from I. bartlettii DORA_8_9 (ETI93048.1, 68.79\%), NOIFHP from Ureibacillus sp. Re31 (WP_191706693.1, 66.67\%), FHP from L. sphaericus C3-41 (ACA41869.1, 65.97\%), Cyo from Clostridium sp. (SCK00776.1, 65.73\%), NOD from C. latum (WP_066464548.1, 65.28\%), and DHPR from B. bacterium VT-13-104 (KKE77556.1, 59.86\%). Hb: hemoglobin; BacA: bacitracin resistance protein; HP: hypothetical protein; NOIFHP: NO-inducible flavohemoprotein; FHP: flavohemoprotein; Cyo: cytochrome $o$; NOD: nitric oxide dioxygenase; DHPR: dihydropteridine reductase; VtHb: VHb, Vitreoscilla hemoglobin; SDgb: single-domain globin; PPK13289: belongs to the superfamily cl36224 and may span more than one domain. FAD: flavin adenine dinucleotide; NAD: nicotinamide adenine dinucleotide; Yhb1-globin_like: a globin domain such as the globin domain of the Saccharomyces cerevisiae flavohemoglobin (Yhb1p). Different colors represent different proteins or domains.

Based on the analysis of conserved domains, the results show that BacA from C. paraputrificum, $\mathrm{Hb}$ from Clostridium sp. CAG:221, and FHP from L. sphaericus C3-41 all contain heme binding sites. Particularly, there are NAD (nicotinamide adenine dinucleotide) and FAD (flavin adenine dinucleotide) binding sites on FHP from L. sphaericus C3-41, which are very similar to the structure of $\mathrm{VHb}$. BacA from $\mathrm{C}$. paraputrificum and $\mathrm{Hb}$ from Clostridium sp. CAG:221 belong to the VtHb-like_SDgb (VHb-like_SDgb) protein family. BacA has the activity of undecaprenyl pyrophosphate phosphatase that is involved in the cell wall synthesis [33]. In addition, BacA can interact with lipids, which is similar to the function of $\mathrm{VHb}$ [24]. HP from I. bartlettii DORA_8_9, NOIFHP from Ureibacillus sp. Re31, FHP from L. sphaericus C3-41, and DHPR from B. bacterium VT-13-104 belong to PPK13289, a member of the $\mathrm{cl} 36224$ protein superfamily and may span more than one domain. Although no conserved domain was obtained by alignment, the function of NO-dioxygenase (NOD) from C. latum and Cyo from Clostridium sp. is similar with VHb [16,25], indicating some potential functional domains still remain to be discovered. 


\section{The Heterologous Expression of $\mathrm{VHb}$}

\subsection{The Regulation of $\mathrm{VHb}$ Expression by Its Native Promoter}

After the $v g b$ gene encoding $\mathrm{VHb}$ was identified in Vitreoscilla [2], $\mathrm{VHb}$ was first heterologously expressed by its native promoter in E. coli [3]. It is worth noting that the expression of $\mathrm{VHb}$ was induced under hypoxic conditions both in Vitreoscilla and E. coli, indicating the oxygen-sensitive regulatory mechanism for its native promoter. In the following, it is found that there are binding sites of the oxygen-responsive transcriptional regulators OxyR, Fnr, ArcA, and Crp on the vgb promoter. Under oxygen-limited conditions, Fnr, ArcA, and Crp activate the expression of the $v g b$ gene independently or in combination to promote oxygen supply and enhance respiratory activity [34]. Under high aeration, OxyR can not only down-regulate the transcription of the $v g b$ gene by binding to the $v g b$ promoter, but also interacts with $\mathrm{VHb}$ to convert it into an oxidized state that can positively regulate the expression of genes involved in oxidative stress and enhance the ability of cells to resist oxidative stress [26].

\subsection{The Strategies to Improve $V H b$ Expression}

Due to the promising effect of oxygen delivery on the growth of strains and the synthesis of useful products, the expression levels of $\mathrm{VHb}$ should be adjusted for different kinds of microbial hosts [35]. At present, three factors that can significantly influence $\mathrm{VHb}$ expression have been optimized, including the copy number of the $v g b$ gene, the vector copy number, and the promoter strength (Table 2).

Table 2. The strategies of $\mathrm{VHb}$ expression.

\begin{tabular}{|c|c|c|}
\hline Strain & Expression Strategies & References \\
\hline Escherichia coli & Free; inducible; $v g b$ promoter & [36] \\
\hline E. coli & Free; inducible; $v g b$ promoter & {$[35]$} \\
\hline E. coli & Free; inducible; P8vgb & [37] \\
\hline $\begin{array}{l}\text { E. coli, Halomonas bluephagenesis } \\
\text { and Halomonas campaniensis }\end{array}$ & Free; inducible; P8vgb & [38] \\
\hline E. coli & Integrative; constitutive; trc promoter & [39] \\
\hline E. coli & Integrative; inducible; trc promoter & {$[40]$} \\
\hline E. coli & Free; inducible; tac promoter & [41] \\
\hline Thialkalivibrio versutus & Free; constitutive; tac promoter & [42] \\
\hline E. coli & Free; constitutive; $t a c$ promoter & [43] \\
\hline Cupriavidus necator & Free; constitutive; $\mathrm{P}_{\mathrm{phaC} 1-\mathrm{j} 5}$ promoter & {$[44]$} \\
\hline Bacillus subtilis & Free; constitutive; $\mathrm{P} 43$ promoter & [45] \\
\hline Aurantiochytrium sp. & Integrative; constitutive; tubulin promoter & [46] \\
\hline Streptomyces sp. & Integrative; constitutive; ermE promoter & [47] \\
\hline Pichia pastoris & Integrative; inducible; $A O X 1$ promoter & [48] \\
\hline P.pastoris & Integrative; inducible; $A O X 1$ promoter & [49] \\
\hline Arabidopsis and Zea mays L. & Integrative; constitutive; CaMV35S promoter & [9] \\
\hline Hyoscyamus niger & Integrative; constitutive; CaMV35S promoter & {$[50]$} \\
\hline
\end{tabular}

Free: intracellular free expression by plasmid; Integrative: intracellular integrative expression by chromosomally integration; Inducible: intracellular inducible expression by the addition of inducers; Constitutive: intracellular constitutive expression that do not need inducers. P8vgb: eight-tandem $v g b$ promoter; $\operatorname{trc}$ promoter: $\operatorname{trp}$ and lac

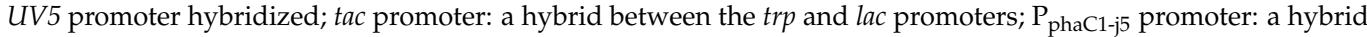
between $\mathrm{P}_{\mathrm{phaC} 1}$ and $\mathrm{P}_{\mathrm{j} 5}$ promoter; tubulin promoter: a promoter amplified from the genome of Aurantiochytrium sp.; ermE promoter: a strong constitutive promoter commonly used in Streptomyces sp.; AOX1 promoter: methanolinducible promoter commonly used in P. pastoris; CaMV35S promoter: the 35S promoter from the plant pathogen cauliflower mosaic virus.

At first, based on the effect of different $\mathrm{VHb}$ expression levels on the growth of E. coli, the suitable copy number of the $v g b$ gene was determined. The result showed that the increased integrated copies of the $v g b$ gene under the control of the $v g b$ promoter cannot improve cell growth [36]. Therefore, the single copy of $v g b$ gene was generally adopted in the following metabolic engineered strains. Next, three different recombinant E. coli strains (harboring low, middle, and high copy numbers of vectors containing the vg $b$ gene, 
respectively) were constructed to improve the titer of ethanol. The results showed that the titer of ethanol was inversely proportional to the expression level of $\mathrm{VHb}$ and the highest titer of ethanol was obtained by the lowest $\mathrm{VHb}$ co-expression [35].

At last, the efficient expression of the $v g b$ gene was achieved by selecting appropriate promoters. The native $v g b$ promoter works in several Gram-negative bacteria, including eight-tandem $v g b$ promoter P8vgb in E. coli, Halomonas bluephagenesis and Halomonas campaniensis $[37,38]$. The specific promoters that have been chosen for other bacteria include trc promoter in E. coli [39,40], tac promoter in E. coli and Thialkalivibrio versutus [41-43],

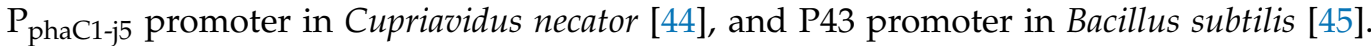
Fungal promoters that have been used for expression in fungi include: tubulin promoter in Aurantiochytrium sp. [46], constitutive ermE promoter in Streptomyces sp. [47], and AOX1 promoter in Pichia pastoris $[48,49]$. In addition, the CaMV35S promoter has been chosen in higher plant systems [9,50].

\section{The Effect of $\mathrm{VHb}$ Expression on Cell Metabolism}

The result of transcriptomics showed that the expression of $\mathrm{VHb}$ can affect hundreds of genes in E. coli, especially for the genes involved in central carbon and energy metabolism [41]. In addition, under the conditions of limited oxygen and glucose as the sole carbon in E. coli, the analysis of metabolic flux distribution further demonstrated that the expression of $\mathrm{VHb}$ leads to dominant carbon flux in the pentose phosphate pathway (PPP), while the remaining carbon flux is guided toward the tricarboxylic acid (TCA) cycle [51]. Further research showed that the TCA cycle in $v g b^{+}$cells of E. coli can function in a branched manner under hypoxic conditions [52]. Along with the increasing carbon flux in PPP, more NADPH was produced and a net NADH flux is generated by the NADH/NADPH transhydrogenase in $v g b^{+}$cells under microaerobic conditions [51]. Moreover, $\mathrm{VHb}$ delivers oxygen to the respiratory chain, the respiratory activity was enhanced, the ratio of $\mathrm{NAD}^{+} / \mathrm{NADH}$ and ATP generation was improved $[7,53]$. Furthermore, by-products in the fermentation process were significantly reduced (acetate $\sim 25 \%$, ethanol $\sim 49 \%$, formate $\sim 68 \%$, lactate $\sim 72 \%$, and succinate $\sim 50 \%$ ) and growth yield increased $35 \%$ in $v g b^{+}$cells [51]. Especially for acetate, the following transcriptional analysis showed that the transcriptional levels of the glyoxylate shunt genes were also decreased [54].

\section{Applications of $\mathrm{VHb}$ in Biotechnology}

Dependent on the robust capacity of oxygen transport under hypoxic conditions, $\mathrm{VHb}$ has been widely used for the improvement of biosynthesis, cell growth and bioremediation (Figure 2).

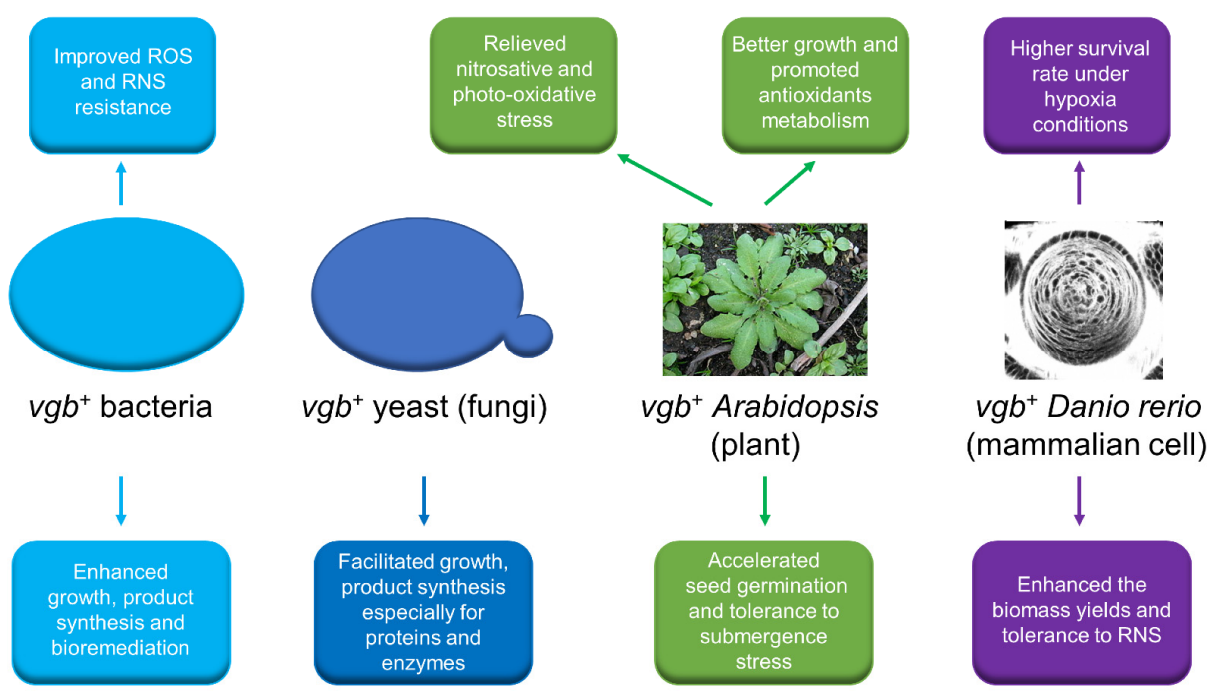

Figure 2. The potential applications of $\mathrm{VHb}$ in the field of metabolic engineering for bacteria [55,56], fungi $[48,49]$, plants [57] and animals [58]. ROS: reactive oxygen species; RNS: reactive nitrogen species. 


\section{1. $\mathrm{VHb}$ in Biotechnological Productions}

$\mathrm{VHb}$ has been used for some important value-added products such as acetoin, butanediol and L-asparaginase under hypoxic conditions. For acetoin and butanediol, the $v g b^{+}$engineered Enterobacter aerogenes showed an enhancement of $83 \%$ in accumulation of acetoin and butanediol compared to the control strain without $v g b$ [59]. In addition, an increase of $70 \%$ on the production of L-asparaginase was achieved in Pseudomonas aeruginosa by introducing the vgb gene [60]. Furthermore, many processes of ethanol production from pure sugars and industrial waste (corn, molasses, whey, whey powder, etc.) can be enhanced by $\mathrm{VHb}$ expression [61]. By combining immobilization with $\mathrm{VHb}$, the immobilized engineered E. coli increased by $47 \%$ in the medium with an intermediate concentration of lactose from whey powder [62]. After the optimization of immobilization conditions ( $10 \%$ bead inoculation) and the medium composition ( $8 \%$ lactose from whey powder), the $v g b^{+}$immobilized E. coli displayed a higher titer of ethanol to $4.64 \%$ [63].

Besides the above-mentioned products, the production of other target products, including antibiotics, enzymes, organic acids and polysaccharides, can also be significantly increased through heterologous expression of $\mathrm{VHb}$ (Table 3). For antibiotics, the synthesis of pyocyanin and rifamycin B can be increased 3-fold in E. coli [64] and 2.2-fold in Amycolatopsis mediterranei [65], respectively. For enzymes, the expression of lipase 2, coenzyme Q10 and xylanase can be enhanced by $87.84 \%$ in P. pastoris [48], 71\% in Rhodobacter sphaeroides [66] and $31 \%$ in P. pastoris [49], respectively. For organic acids, the $\mathrm{VHb}$ expression has a greater effect on arachidonic acid (8-fold) in Mortierella alpina [67], docosahexaenoic acid (2.74-fold) in Aurantiochytrium sp. [68], and ganoderic acid (1.4-fold) in G. lucidum [69]. For polysaccharides, several complex compounds, including bacterial cellulose (58.6\%) in Gluconacetobacter xylinus [70], pullulan (42.08\%) in Aureobasidium melanogenum [71], $\beta$-glucan (12.9-24.0\%) in Lentinula edodes [72], and 6-(N-hydroxyethyl)-amino-6-deoxy-alpha-l-sorbofuranose $(11.89 \%)$ in Gluconobacter oxydans [10] can be efficiently obtained, respectively.

Table 3. The titer of products increased by the expression of $\mathrm{VHb}$.

\begin{tabular}{|c|c|c|c|c|}
\hline & Products & Enhancement & Strain & References \\
\hline \multirow{7}{*}{ Alcohols } & \multirow{5}{*}{ Ethanol } & $\sim 362 \%$ & E. coli & [73] \\
\hline & & $\sim 118 \%$ & E. coli & [35] \\
\hline & & $\sim 60 \%$ & E. coli & [74] \\
\hline & & $\sim 47 \%$ & E. coli & [62] \\
\hline & & $\sim(41-83 \%)$ & E. coli & [63] \\
\hline & Butanediol & $\sim 83 \%$ & Enterobacter aerogenes & [59] \\
\hline & Erythritol & $\sim 26.13 \%$ & Yarrowia lipolytica & [75] \\
\hline \multirow{2}{*}{ Antibiotics } & Pyocyanin & $\sim 3$-fold & E. coli & [64] \\
\hline & Rifamycin B & $\sim 2.2$-fold & Amycolatopsis mediterranei & {$[65]$} \\
\hline \multirow{4}{*}{ Enzymes } & Lipase 2 & $\sim 87.84 \%$ & P. pastoris & [48] \\
\hline & Coenzyme Q10 & $\sim 71 \%$ & Rhodobacter sphaeroides & [66] \\
\hline & Xylanase & $\sim 31 \%$ & P. pastoris & [49] \\
\hline & L-asparaginase & $\sim 70 \%$ & Pseudomonas aeruginosa & {$[60]$} \\
\hline \multirow{6}{*}{ Acids } & Arachidonic acid & $\sim 8$-fold & Mortierella alpina & [67] \\
\hline & Docosahexaenoic acid & 2.74-fold & Aurantiochytrium sp. & [68] \\
\hline & Ganoderic acid & $\sim 1.4$-fold & Ganoderma lucidum & [69] \\
\hline & S-adenosylmethionine & $\sim 67 \%$ & S. cerevisiae & [76] \\
\hline & Glucaric acid & $\sim 28.76 \%$ & S. cerevisiae & [77] \\
\hline & L-phenylalanine & $\sim 16.6 \%$ & E. coli & [43] \\
\hline \multirow{4}{*}{ Polysaccharides } & Bacterial cellulose & $\sim 58.6 \%$ & Gluconacetobacter xylinus & [70] \\
\hline & Pullulan & $\sim 42.08 \%$ & Aureobasidium melanogenum & [71] \\
\hline & $\beta$-glucan & $\sim(12.9-24.0 \%)$ & Lentinula edodes & [72] \\
\hline & $\begin{array}{l}\text { 6-(N-hydroxyethyl)-amino-6-deoxy- } \\
\text { alpha-l-sorbofuranose }\end{array}$ & $\sim 11.89 \%$ & Gluconobacter oxydans & {$[10]$} \\
\hline \multirow{2}{*}{ Others } & Polyhydroxybutyrate & $\sim 71.5 \%$ & C. necator & [44] \\
\hline & Acetoin & $\sim 83 \%$ & Enterobacter aerogenes & [59] \\
\hline
\end{tabular}

Enhancement: the ratio of the increase in the product titer of $v g b^{+}$strain relative to the control (\% or fold). 


\section{2. $\mathrm{VHb}$ in Plants}

The expression of $\mathrm{VHb}$ was also used to improve the waterlogging tolerance of higher plants. Under waterlogging conditions, $\mathrm{VHb}$ expressed in Zea mays L. seedlings can induce a higher activity of peroxidase and alcohol dehydrogenase 1 that are correlation with tolerance to oxidative stress and enhance the growth performance of plants (seedling height, root dry weight, primary root length, etc.) [9]. In addition, the expression of $\mathrm{VHb}$ can regulate the transcription of endogenous genes that refer to antioxidant biosynthesis and oxygen metabolism in plant cells, and protect cells from oxidative damage [57]. Furthermore, the biosynthesis of ascorbate and the tolerance to photo-oxidative stress were enhanced in $\mathrm{VHb}$-expressing Arabidopsis cells [57]. $\mathrm{VHb}$ also plays a positive role in some other higher plants, including the enhancement of productivity and resistance to the herbicide glyphosate in Oryza sativa L. [78], and the improvement of seed germination and tolerance to submergence stress in cabbage (Brassica oleracea var. capitata L.) [79]. However, the expression of $\mathrm{VHb}$ does not always have a positive effect on plants. In the case of Hordeum vulgare, it exhibited a slower germination rate and impaired rooting of seedlings, which may be attributed to the removal of a significant signaling molecule (NO) related to seed germination and root formation by $\mathrm{VHb}$ [80]. In addition, the introduction of the $v g b$ gene into Populus alba $\mathrm{L}$. did not improve tolerance to submergence, oxidative and nitrosative stresses [81]. Therefore, it is necessary to carefully investigate the influence of the genetic manipulation of oxygen metabolism of higher plants on the physiological and biochemical characteristics of cells in order to evaluate the true value of $\mathrm{VHb}$ application for higher plants.

\subsection{VHb in Mammalian Cells}

There are also several successful reports on the application of $\mathrm{VHb}$ engineering in animal cells, including increased tissue plasminogen activator $(\sim 40-100 \%)$ in Chinese hamster ovary cells [82], increased survival rate $\left(v g b^{+}-34.57 \sim 92 \%\right.$ and $\left.v g b^{-}-15.69 \sim 65 \%\right)$ in Danio rerio [58], and increased biomass yields by $60 \%$ and lactate decrease of $40 \%$ in Chinese hamster ovary cells [7]. Since the metabolism of animals is much more complicated than that of microorganisms, the application of $\mathrm{VHb}$ in the field of animals has been relatively slow in recent years.

\section{4. $\mathrm{VHb}$ in Biodegradation Applications}

$\mathrm{VHb}$ expression was frequently applied in biodesulfurization, degradation of pesticides, and wastewater treatment (Table 4). Dependent on the function of sulfide receptor and storage [23], the expression of $\mathrm{VHb}$ in Rhodococcus erythropolis (desulfurization bacterium) presented a higher desulfurization ratio than the control $\left(v g b^{+}-37.5 \%\right.$ and $v g b^{-}$$20.5 \%$ ) under hypoxic conditions [83]. In the following, an increase of $11.7 \pm 1.8 \%$ on the rate of thiosulfate scavenge was achieved in T. versutus by introducing the vgb gene [42]. In addition, the co-culture of desulfurization bacteria is also an effective sulfur degradation method [84]. For example, co-culture of Paenibacillus strains $\left(v \mathrm{gb}^{+}\right)$showed a stronger growth than the control $\left(\mathrm{vg} b^{-}\right)$under the conditions of dibenzothiophene [11]. Moreover, introduction of the $v g b$ gene into Pseudomonas putida can improve its pesticide degradation function under oxygen-limited conditions, including simultaneous degradation of methyl $\gamma$ hexachlorocyclohexane and parathion [85], the removal of 1,2,3-trichloropropane [86], and the simultaneous elimination of carbamates, pyrethroids, and organophosphates [87]. As for wastewater treatment, the $v g b^{+}$engineered Burkholderia cepacia strain was first applied with a parallel membrane bioreactors system and displayed a significant increase in the degradation efficiency of 2-chlorobenzoic acid ( $v g b^{+} \sim 94-97 \%$ and $v g b^{-} \sim 67-85 \%$ ) [88]. In addition, based on the activity of peroxidase, one of the $\mathrm{VHb}$ variants $(\mathrm{Q} 53 \mathrm{H} / \mathrm{P} 54 \mathrm{C})$ shows excellent prospects for treating wastewater contaminated by textile dyes [21]. Furthermore, the $b$-type heme derived from $\mathrm{VHb}$ is quite beneficial for the activity of hemoglobin in activated sludge, which functions as oxidase or peroxidase and plays an important role in traditional aerobic wastewater treatment [89]. 
Table 4. The applications of $\mathrm{VHb}$ in biodegradation.

\begin{tabular}{ccc}
\hline Compounds & Strain & References \\
\hline Dibenzothiophene & Rhodococcus erythropolis & {$[83]$} \\
Thiosulfate & T. versutus & {$[42]$} \\
Dibenzothiophene & Paenibacillus & {$[11]$} \\
Pesticides & Pseudomonas putida & {$[85-87]$} \\
2-chlorobenzoic acid & Burkholderia cepacia & {$[88]$} \\
Benzene, toluene and xylene & Pseudomonas aeruginosa & {$[90]$} \\
Cadmium & Enterobacter aerogenes & {$[91]$} \\
\hline
\end{tabular}

\section{Conclusions and Future Perspectives}

$\mathrm{VHb}$ is a special bacterial hemoglobin that can interact with terminal oxidase to provide enough oxygen for cell growth. Based on analyses of its properties and crystal structures, $\mathrm{VHb}$ has been applied in the field of metabolic engineering for microorganisms, plants, and animals to achieve high-cell-density fermentation and to enhance product synthesis and stress tolerance under oxygen-limited conditions. By the optimization of its expression strategies, the effect of $\mathrm{VHb}$ was further improved, allowing $\mathrm{VHb}$ technology to be used for more and more products.

In the future, there are four possible directions for the development of $\mathrm{VHb}$ application. Firstly, the precursors of heme (5-aminolevulinic acid) could be supplemented or the biosynthesis of heme could be enhanced to increase the activity of $\mathrm{VHb}$ because many microorganisms cannot supply enough heme for $\mathrm{VHb}$ expression. In the case of eukaryotic hemoglobins, the active Arenicola Marina globin chains were efficiently expressed by the addition of 5-aminolevulinic acid in E. coli [92]. In addition, an improvement of human hemoglobin production was obtained in S. cerevisiae with an enhanced heme synthesis pathway [93]. Secondly, the addition of iron and transport of iron over cell membranes also have a positive effect on hemoglobin production. The hemoglobin of $\beta$-thalassemic mice was increased with the exogenous addition of iron [94]. Thirdly, more and more $\mathrm{VHb}$ mutants with improved characteristics can be selected by protein engineering and high throughput screening. Furthermore, the expression of $\mathrm{VHb}$ will also contribute extra metabolic burden, but the optimization of promoter, substrate and inducer can significantly relieve this adverse effect on the host $[95,96]$. Finally, more research on the regulatory mechanism of $\mathrm{VHb}$ on oxygen-response is needed to expand its application in other areas.

Author Contributions: Conceptualization, F.Y. and X.Z.; writing-original draft preparation, F.Y., Z.W., L.L. and L.Y.; writing-review and editing, F.Y. and X.Z.; supervision, X.Z., J.Z., J.L., J.C. and G.D. All authors have read and agreed to the published version of the manuscript.

Funding: This research was funded by the National Key Research and Development Program of China (2021YFC2101400), the National First-Class Discipline Program of Light Industry Technology and Engineering (LITE2018-08), the National Natural Science Foundation of China (31900067), and the Fundamental Research Funds for the Central Universities (JUSRP52021).

Conflicts of Interest: The authors declare no conflict of interest.

\section{References}

1. Webster, D.A.; Hackett, D.P. The Purification and Properties of Cytochrome o from Vitreoscilla. J. Biol. Chem. 1966, 241, 3308-3315. [CrossRef]

2. Wakabayashi, S.; Matsubara, H.; Webster, D.A. Primary sequence of a dimeric bacterial haemoglobin from Vitreoscilla. Nature 1986, 322, 481-483. [CrossRef]

3. Khosla, C.; Bailey, J.E. The Vitreoscilla hemoglobin gene: Molecular cloning, nucleotide sequence and genetic expression in Escherichia coli. Mol. Gen. Genet. 1988, 214, 158-161. [CrossRef]

4. Webster, D.A.; Liu, C.Y. Reduced nicotinamide adenine dinucleotide cytochrome o reductase associated with cytochrome $o$ purified from Vitreoscilla. Evidence for an intermediate oxygenated form of cytochrome o. J. Biol. Chem. 1974, 249, 4257-4260. [CrossRef] 
5. Tyree, B.; Webster, D.A.; Tyree, B. The binding of cyanide and carbon monoxide to cytochrome o purified from Vitreoscilla. Evidence for subunit interaction in the reduced protein. J. Biol. Chem. 1978, 253, 6988-6991. [CrossRef]

6. Stark, B.C.; Pagilla, K.R.; Dikshit, K.L. Recent applications of Vitreoscilla hemoglobin technology in bioproduct synthesis and bioremediation. Appl. Microbiol. Biotechnol. 2015, 99, 1627-1636. [CrossRef]

7. Juárez, M.; La Rosa, C.H.G.-D.; Memún, E.; Sigala, J.-C.; Lara, A.R. Aerobic expression of Vitreoscilla hemoglobin improves the growth performance of CHO-K1 cells. Biotechnol. J. 2017, 12, 1600438. [CrossRef]

8. Chen, Y.; Chen, X.-Y.; Du, H.-T.; Zhang, X.; Ma, Y.-M.; Chen, J.-C.; Ye, J.-W.; Jiang, X.-R.; Chen, G.-Q. Chromosome engineering of the TCA cycle in Halomonas bluephagenesis for production of copolymers of 3-hydroxybutyrate and 3-hydroxyvalerate (PHBV). Metab. Eng. 2019, 54, 69-82. [CrossRef]

9. Du, H.; Shen, X.; Huang, Y.; Huang, M.; Zhang, Z. Overexpression of Vitreoscilla hemoglobin increases waterlogging tolerance in Arabidopsis and maize. BMC Plant Biol. 2016, 16, 35. [CrossRef]

10. Liu, D.; Ke, X.; Hu, Z.-C.; Zheng, Y.-G. Improvement of pyrroloquinoline quinone-dependent d-sorbitol dehydrogenase activity from Gluconobacter oxydans via expression of Vitreoscilla hemoglobin and regulation of dissolved oxygen tension for the biosynthesis of 6-(N-hydroxyethyl)-amino-6-deoxy- $\alpha$-L-sorbofuranose. J. Biosci. Bioeng. 2021, 131, 518-524. [CrossRef]

11. Sar, T.; Chen, Y.; Bai, Y.; Liu, B.; Agarwal, P.; Stark, B.C.; Akbas, M.Y. Combining co-culturing of Paenibacillus strains and Vitreoscilla hemoglobin expression as a strategy to improve biodesulfurization. Lett. Appl. Microbiol. 2021, 72, 484-494. [CrossRef]

12. Orii, Y.; Webster, D.A. Photodissociation of oxygenated cytochrome o(s) (Vitreoscilla) and kinetic studies of reassociation. J. Biol. Chem. 1986, 261, 3544-3547. [CrossRef]

13. Webster, D.A. Structure and function of bacterial hemoglobin and related proteins. Adv. Inorg. Biochem. 1988, 7, $245-265$.

14. Ramandeep; Hwang, K.W.; Raje, M.; Kim, K.J.; Stark, B.C.; Dikshit, K.L.; Webster, D.A. Vitreoscilla hemoglobin. Intracellular localization and binding to membranes. J. Biol. Chem. 2001, 276, 24781-24789. [CrossRef] [PubMed]

15. Park, K.-W.; Kim, K.-J.; Howard, A.J.; Stark, B.C.; Webster, D.A. Vitreoscilla Hemoglobin Binds to Subunit I of Cytochrome bo Ubiquinol Oxidases. J. Biol. Chem. 2002, 277, 33334-33337. [CrossRef] [PubMed]

16. Dikshit, R.P.; Dikshit, K.L.; Liu, Y.; Webster, D.A. The bacterial hemoglobin from Vitreoscilla can support the aerobic growth of Escherichia coli lacking terminal oxidases. Arch. Biochem. Biophys. 1992, 293, 241-245. [CrossRef]

17. Kvist, M.; Ryabova, E.S.; Nordlander, E.; Bülow, L. An investigation of the peroxidase activity of Vitreoscilla hemoglobin. J. Biol. Inorg. Chem. 2007, 12, 324-334. [CrossRef] [PubMed]

18. Li, W.; Zhang, Y.; Xu, H.; Wu, L.; Cao, Y.; Zhao, H.; Li, Z. pH-induced quaternary assembly of Vitreoscilla hemoglobin: The monomer exhibits better peroxidase activity. Biochim. Biophys. Acta. 2013, 1834, 2124-2132. [CrossRef]

19. Suwanwong, Y.; Kvist, M.; Isarankura-Na-Ayudhya, C.; Tansila, N.; Bulow, L.; Prachayasittikul, V. Chimeric Antibody-Binding Vitreoscilla Hemoglobin ( $(\mathrm{hb})$ Mediates Redox-Catalysis Reaction: New Insight into the Functional Role of VHb. Int. J. Biol. Sci. 2006, 2, 208-215. [CrossRef]

20. Isarankura-Na-Ayudhya, C.; Tansila, N.; Worachartcheewan, A.; Bülow, L.; Prachayasittikul, V. Biochemical and cellular investigation of Vitreoscilla hemoglobin $(\tau h b)$ variants possessing efficient peroxidase activity. J. Microbiol. Biotechnol. 2010, 20, 532-541.

21. Zhang, Z.; Li, W.; Li, H.; Zhang, J.; Zhang, Y.; Cao, Y.; Ma, J.; Li, Z. Construction and Characterization of Vitreoscilla Hemoglobin (vhb) with Enhanced Peroxidase Activity for Efficient Degradation of Textile Dye. J. Microbiol. Biotechnol. 2015, 25, $1433-1441$. [CrossRef]

22. Ramos-Alvarez, C.; Yoo, B.K.; Pietri, R.; Lamarre, I.; Martin, J.L.; Lopez-Garriga, J.; Negrerie, M. Reactivity and dynamics of $\mathrm{H}_{2} \mathrm{~S}$, $\mathrm{NO}$, and $\mathrm{O}_{2}$ interacting with hemoglobins from Lucina pectinata. Biochemistry 2013, 52, 7007-7021. [CrossRef] [PubMed]

23. Wang, D.; Liu, L.; Wang, H.; Xu, H.; Chen, L.; Ma, L.; Li, Z. Clues for discovering a new biological function of Vitreoscilla hemoglobin in organisms: Potential sulfide receptor and storage. FEBS Lett. 2016, 590, 1132-1142. [CrossRef]

24. Rinaldi, A.C.; Bonamore, A.; Macone, A.; Boffi, A.; Bozzi, A.; Di Giulio, A. Interaction of Vitreoscilla Hemoglobin with Membrane Lipids. Biochemistry 2006, 45, 4069-4076. [CrossRef]

25. Kaur, R.; Pathania, R.; Sharma, V.; Mande, S.C.; Dikshit, K.L. Chimeric Vitreoscilla Hemoglobin (vhb) Carrying a Flavoreductase Domain Relieves Nitrosative Stress in Escherichia coli: New Insight into the Functional Role of VHb. Appl. Environ. Microbiol. 2002, 68, 152-160. [CrossRef]

26. Anand, A.; Duk, B.T.; Singh, S.; Akbas, M.Y.; Webster, D.A.; Stark, B.C.; Dikshit, K.L. Redox-mediated interactions of VHb (Vitreoscilla haemoglobin) with OxyR: Novel regulation of VHb biosynthesis under oxidative stress. Biochem. J. 2010, 426, 271-280. [CrossRef]

27. Lin, J.-M.; Stark, B.C.; Webster, D.A. Effects of Vitreoscilla hemoglobin on the 2,4-dinitrotoluene (2,4-DNT) dioxygenase activity of Burkholderia and on 2,4-DNT degradation in two-phase bioreactors. J. Ind. Microbiol. Biotechnol. 2003, 30, 362-368. [CrossRef]

28. Tarricone, C.; Galizzi, A.; Coda, A.; Ascenzi, P.; Bolognesi, M. Unusual structure of the oxygen-binding site in the dimeric bacterial hemoglobin from Vitreoscilla sp. Structure 1997, 5, 497-507. [CrossRef]

29. Bolognesi, M.; Boffi, A.; Coletta, M.; Mozzarelli, A.; Pesce, A.; Tarricone, C.; Ascenzi, P. Anticooperative ligand binding properties of recombinant ferric Vitreoscilla homodimeric hemoglobin: A thermodynamic, kinetic and X-ray crystallographic study. J. Mol. Biol. 1999, 291, 637-650. [CrossRef] 
30. Dikshit, K.L.; Orii, Y.; Navani, N.; Patel, S.; Huang, H.Y.; Stark, B.C.; Webster, D.A. Site-directed mutagenesis of bacterial hemoglobin: The role of glutamine (E7) in oxygen-binding in the distal heme pocket. Arch. Biochem. Biophys. 1998, 349, 161-166. [CrossRef]

31. Ratakonda, S.; Anand, A.; Dikshit, K.; Stark, B.C.; Howard, A.J. Crystallographic structure determination of B10 mutants of Vitreoscilla hemoglobin: Role of Tyr29 (B10) in the structure of the ligand-binding site. Acta Crystallogr. Sect. F Struct. Biol. Cryst. Commun. 2013, 69, 215-222. [CrossRef]

32. Kaur, R.; Ahuja, S.; Anand, A.; Singh, B.; Stark, B.C.; Webster, D.A.; Dikshit, K.L. Functional implications of the proximal site hydrogen bonding network in Vitreoscilla hemoglobin (vhb): Role of Tyr95 (G5) and Tyr126 (H12). FEBS Lett. 2008, 582, 3494-3500. [CrossRef]

33. El Ghachi, M.; Bouhss, A.; Blanot, D.; Mengin-Lecreulx, D. The bacA Gene of Escherichia coli Encodes an Undecaprenyl Pyrophosphate Phosphatase Activity. J. Biol. Chem. 2004, 279, 30106-30113. [CrossRef]

34. Yang, J.; Webster, D.A.; Stark, B.C. ArcA works with Fnr as a positive regulator of Vitreoscilla (bacterial) hemoglobin gene expression in Escherichia coli. Microbiol. Res. 2005, 160, 405-415. [CrossRef] [PubMed]

35. Sanny, T.; Arnaldos, M.; Kunkel, S.A.; Pagilla, K.; Stark, B.C. Engineering of ethanolic E. coli with the Vitreoscilla hemoglobin gene enhances ethanol production from both glucose and xylose. Appl. Microbiol. Biotechnol. 2010, 88, 1103-1112. [CrossRef]

36. Khosla, C.; Curtis, J.E.; DeModena, J.; Rinas, U.; Bailey, J.E. Expression of Intracellular Hemoglobin Improves Protein Synthesis in Oxygen-Limited Escherichia coli. Nat. Biotechnol. 1990, 8, 849-853. [CrossRef]

37. Wu, H.; Wang, H.; Chen, J.; Chen, G.-Q. Effects of cascaded vgb promoters on poly(hydroxybutyrate) (PHB) synthesis by recombinant Escherichia coli grown micro-aerobically. Appl. Microbiol. Biotechnol. 2014, 98, 10013-10021. [CrossRef]

38. Ouyang, P.; Wang, H.; Hajnal, I.; Wu, Q.; Guo, Y.; Chen, G.-Q. Increasing oxygen availability for improving poly(3hydroxybutyrate) production by Halomonas. Metab. Eng. 2018, 45, 20-31. [CrossRef] [PubMed]

39. Lara, A.R.; Velázquez, D.; Penella, I.; Islas, F.; La Rosa, C.H.G.-D.; Sigala, J.-C. Design of a synthetic miniR1 plasmid and its production by engineered Escherichia coli. Bioprocess Biosyst. Eng. 2019, 42, 1391-1397. [CrossRef]

40. Jaén, K.E.; Velazquez, D.; Delvigne, F.; Sigala, J.-C.; Lara, A.R. Engineering E. coli for improved microaerobic pDNA production. Bioprocess Biosyst. Eng. 2019, 42, 1457-1466. [CrossRef]

41. Roos, V.; Andersson, C.I.; Bülow, L. Gene expression profiling of Escherichia coli expressing double Vitreoscilla haemoglobin. J. Biotechnol. 2004, 114, 107-120. [CrossRef] [PubMed]

42. Mu, T.; Yang, M.; Zhao, J.; Sharshar, M.M.; Tian, J.; Xing, J. Improvement of desulfurizing activity of haloalkaliphilic Thialkalivibrio versutus SOB306 with the expression of Vitreoscilla hemoglobin gene. Biotechnol. Lett. 2016, 39, 447-452. [CrossRef]

43. Wu, W.; Guo, X.; Zhang, M.; Huang, Q.; Qi, F.; Huang, J. Enhancement of 1 -phenylalanine production in Escherichia coli by heterologous expression of Vitreoscilla hemoglobin. Biotechnol. Appl. Biochem. 2017, 65, 476-483. [CrossRef] [PubMed]

44. Tang, R.; Weng, C.; Peng, X.; Han, Y. Metabolic engineering of Cupriavidus necator H16 for improved chemoautotrophic growth and PHB production under oxygen-limiting conditions. Metab. Eng. 2020, 61, 11-23. [CrossRef]

45. Vyas, R.; Pandya, M.; Pohnerkar, J.; Kumar, G.N. Vitreoscilla hemoglobin promotes biofilm expansion and mitigates sporulation in Bacillus subtilis DK1042. 3 Biotech 2020, 10, 1-7. [CrossRef]

46. Suen, Y.L.; Tang, H.; Huang, J.; Chen, F. Enhanced production of fatty acids and astaxanthin in Aurantiochytrium sp. by the expression of Vitreoscilla hemoglobin. J. Agric. Food Chem. 2014, 62, 12392-12398. [CrossRef]

47. Wang, T.; Bai, L.; Zhu, D.; Lei, X.; Liu, G.; Deng, Z.; You, D. Enhancing macrolide production in Streptomyces by coexpressing three heterologous genes. Enzym. Microb. Technol. 2012, 50, 5-9. [CrossRef]

48. Zhou, Q.; Su, Z.; Jiao, L.; Wang, Y.; Yang, K.; Li, W.; Yan, Y. High-Level Production of a Thermostable Mutant of Yarrowia lipolytica Lipase 2 in Pichia Pastoris. Int. J. Mol. Sci. 2019, 21, 279. [CrossRef]

49. Wang, J.; Li, Y.; Liu, D. Improved production of Aspergillus usamii endo-beta-1,4-Xylanase in Pichia Pastoris via combined strategies. Biomed. Res. Int. 2016, 2016, 3265895.

50. Guo, Z.; Tan, H.; Lv, Z.; Ji, Q.; Huang, Y.; Liu, J.; Chen, D.; Diao, Y.; Si, J.; Zhang, L. Targeted expression of Vitreoscilla hemoglobin improves the production of tropane alkaloids in Hyoscyamus niger hairy roots. Sci. Rep. 2018, 8, 17969. [CrossRef]

51. Tsai, P.S.; Hatzimanikatis, V.; Bailey, J.E. Effect of Vitreoscilla hemoglobin dosage on microaerobic Escherichia coli carbon and energy metabolism. Biotechnol. Bioeng. 1996, 49, 139-150. [CrossRef]

52. Frey, A.; Fiaux, J.; Szyperski, T.; Wüthrich, K.; Bailey, J.E.; Kallio, P.T. Dissection of Central Carbon Metabolism of HemoglobinExpressing Escherichia coli by 13C Nuclear Magnetic Resonance Flux Distribution Analysis in Microaerobic Bioprocesses. Appl. Environ. Microbiol. 2001, 67, 680-687. [CrossRef] [PubMed]

53. Cai, D.; Chen, Y.; He, P.; Wang, S.; Mo, F.; Li, X.; Wang, Q.; Nomura, C.T.; Wen, Z.; Ma, X.; et al. Enhanced production of poly-gamma-glutamic acid by improving ATP supply in metabolically engineered Bacillus licheniformis. Biotechnol. Bioeng. 2018, 115, 2541-2553. [CrossRef] [PubMed]

54. Lara, A.R.; Galindo, J.; Jaén, K.E.; Juárez, M.; Sigala, J.-C. Physiological Response of Escherichia coli W3110 and BL21 to the Aerobic Expression of Vitreoscilla Hemoglobin. J. Microbiol. Biotechnol. 2020, 30, 1592-1596. [CrossRef]

55. Frey, A.D.; Koskenkorva, T.; Kallio, P.T. Vitreoscilla hemoglobin promoter is not responsive to nitrosative and oxidative stress in Escherichia coli. FEMS Microbiol. Lett. 2003, 224, 127-132. [CrossRef]

56. Kallio, P.T.; Bollinger, C.J.; Koskenkorva, T.; Frey, A.D. Assessment of Biotechnologically Relevant Characteristics of Heterologous Hemoglobins in E. coli. Methods Enzymol. 2008, 436, 255-272. [CrossRef] 
57. Wang, Z.; Xiao, Y.; Chen, W.; Tang, K.; Zhang, L. Functional expression of Vitreoscilla hemoglobin (vhb) in Arabidopsis relieves submergence, nitrosative, photo-oxidative stress and enhances antioxidants metabolism. Plant Sci. 2009, 176, 66-77. [CrossRef]

58. Guan, B.; Ma, H.; Wang, Y.; Hu, Y.; Lin, Z.; Zhu, Z.; Hu, W. Vitreoscilla Hemoglobin (vhb) Overexpression Increases Hypoxia Tolerance in Zebrafish (Danio rerio). Mar. Biotechnol. 2010, 13, 336-344. [CrossRef]

59. Geckil, H.; Barak, Z.; Chipman, D.M.; Erenler, S.O.; Webster, D.A.; Stark, B.C. Enhanced production of acetoin and butanediol in recombinant Enterobacter aerogenes carrying Vitreoscilla hemoglobin gene. Bioprocess Biosyst. Eng. 2004, 26, 325-330. [CrossRef]

60. Geckil, H.; Gencer, S.; Ates, B.; Ozer, U.; Uckun, M.; Yilmaz, I. Effect of Vitreoscilla hemoglobin on production of a chemotherapeutic enzyme, L-asparaginase, by Pseudomonas aeruginosa. Biotechnol. J. 2006, 1, 203-208. [CrossRef]

61. Akbas, M.Y.; Stark, B.C. Recent trends in bioethanol production from food processing byproducts. J. Ind. Microbiol. Biotechnol. 2016, 43, 1593-1609. [CrossRef]

62. Sar, T.; Stark, B.C.; Akbas, M.Y. Effective ethanol production from whey powder through immobilized E. coli expressing Vitreoscilla hemoglobin. Bioengineered 2016, 8, 171-181. [CrossRef]

63. Sar, T.; Stark, B.C.; Akbas, M.Y. Bioethanol production from whey powder by immobilized E. coli expressing Vitreoscilla hemoglobin: Optimization of sugar concentration and inoculum size. Biofuels 2019. [CrossRef]

64. da Silva, A.J.; Cunha, J.S.; Hreha, T.; Micocci, K.C.; Selistre-De-Araujo, H.S.; Barquera, B.; Koffas, M.A. Metabolic engineering of E. coli for pyocyanin production. Metab. Eng. 2021, 64, 15-25. [CrossRef] [PubMed]

65. Mejía, A.; Luna, D.; Fernández, F.J.; Barrios-González, J.; Gutierrez, L.H.; Reyes, A.G.; Absalón, A.E.; Kelly, S. Improving rifamycin production in Amycolatopsis mediterranei by expressing a Vitreoscilla hemoglobin (vhb) gene fused to a cytochrome P450 monooxygenase domain. 3 Biotech. 2018, 8, 456. [CrossRef] [PubMed]

66. Zhu, Y.; Ye, L.; Chen, Z.; Hu, W.; Shi, Y.; Chen, J.; Wang, C.; Li, Y.; Li, W.; Yu, H. Synergic regulation of redox potential and oxygen uptake to enhance production of coenzyme Q 10 in Rhodobacter sphaeroides. Enzym. Microb. Technol. 2017, 101, 36-43. [CrossRef] [PubMed]

67. Zhang, H.; Feng, Y.; Cui, Q.; Song, X. Expression of Vitreoscilla hemoglobin enhances production of arachidonic acid and lipids in Mortierella alpina. BMC Biotechnol. 2017, 17, 68. [CrossRef]

68. Ye, J.; Liu, M.; He, M.; Ye, Y.; Huang, J. Illustrating and Enhancing the Biosynthesis of Astaxanthin and Docosahexaenoic Acid in Aurantiochytrium sp. SK4. Mar. Drugs 2019, 17, 45. [CrossRef]

69. Li, H.-J.; He, Y.-L.; Zhang, D.-H.; Yue, T.-H.; Jiang, L.-X.; Li, N.; Xu, J.-W. Enhancement of ganoderic acid production by constitutively expressing Vitreoscilla hemoglobin gene in Ganoderma lucidum. J. Biotechnol. 2016, 227, 35-40. [CrossRef]

70. Liu, M.; Li, S.; Xie, Y.; Jia, S.; Hou, Y.; Zou, Y.; Zhong, C. Enhanced bacterial cellulose production by Gluconacetobacter xylinus via expression of Vitreoscilla hemoglobin and oxygen tension regulation. Appl. Microbiol. Biotechnol. 2018, 102, 1155-1165. [CrossRef]

71. Xue, S.-J.; Jiang, H.; Chen, L.; Ge, N.; Liu, G.-L.; Hu, Z.; Chi, Z.-M.; Chi, Z. Over-expression of Vitreoscilla hemoglobin (vhb) and flavohemoglobin $(\mathrm{FHb})$ genes greatly enhances pullulan production. Int. J. Biol. Macromol. 2019, 132, 701-709. [CrossRef] [PubMed]

72. Wang, X.; Ding, Y.; Gao, X.; Liu, H.; Zhao, K.; Gao, Y.; Qiu, L. Promotion of the growth and plant biomass degrading enzymes production in solid-state cultures of Lentinula edodes expressing Vitreoscilla hemoglobin gene. J. Biotechnol. 2019, 302, 42-47. [CrossRef] [PubMed]

73. Akbas, M.Y.; Sar, T.; Ozcelik, B. Improved ethanol production from cheese whey, whey powder, and sugar beet molasses by "Vitreoscilla hemoglobin expressing" Escherichia coli. Biosci. Biotechnol. Biochem. 2014, 78, 687-694. [CrossRef] [PubMed]

74. Arnaldos, M.; Kunkel, S.A.; Wang, J.; Pagilla, K.; Stark, B.C. Vitreoscilla hemoglobin enhances ethanol production by Escherichia coli in a variety of growth media. Biomass Bioenergy 2012, 37, 1-8. [CrossRef]

75. Mirończuk, A.M.; Kosiorowska, K.E.; Biegalska, A.; Rakicka-Pustułka, M.; Szczepańczyk, M.; Dobrowolski, A. Heterologous overexpression of bacterial hemoglobin $\mathrm{VHb}$ improves erythritol biosynthesis by yeast Yarrowia lipolytica. Microb. Cell Factories 2019, 18, 1-8. [CrossRef]

76. Chen, Y.; Tan, T. Enhanced S-Adenosylmethionine Production by Increasing ATP Levels in Baker's Yeast (Saccharomyces cerevisiae). J. Agric. Food Chem. 2018, 66, 5200-5209. [CrossRef]

77. Zhang, X.; Xu, C.; Liu, Y.; Wang, J.; Zhao, Y.; Deng, Y. Enhancement of glucaric acid production in Saccharomyces cerevisiae by expressing Vitreoscilla hemoglobin. Biotechnol. Lett. 2020, 42, 2169-2178. [CrossRef]

78. Cao, M.X.; Huang, J.Q.; Wei, Z.M.; Yao, Q.H.; Wan, C.Z.; Lu, J.A. Engineering Higher Yield and Herbicide Resistance in Rice by Agrobacterium-Mediated Multiple Gene Transformation. Crop. Sci. 2004, 44, 2206-2213. [CrossRef]

79. Li, X.; Peng, R.-H.; Fan, H.-Q.; Xiong, A.-S.; Yao, Q.-H.; Cheng, Z.-M.; Li, Y. Vitreoscilla hemoglobin overexpression increases submergence tolerance in cabbage. Plant Cell Rep. 2005, 23, 710-715. [CrossRef]

80. Wilhelmson, A.; Kallio, P.T.; Oksman-Caldentey, K.-M.; Nuutila, A.M. Heterologous expression of Vitreoscilla haemoglobin in barley (Hordeum vulgare). Plant Cell Rep. 2007, 26, 1773-1783. [CrossRef]

81. Zelasco, S.; Reggi, S.; Calligari, P.; Balestrazzi, A.; Bongiorni, C.; Quattrini, E.; Delia, G.; Bisoffi, S.; Fogher, C.; Confalonieri, M. Expression of the Vitreoscilla Hemoglobin ( $\mathrm{VHb}$ )-Encoding Gene in Transgenic White Poplar: Plant Growth and Biomass Production, Biochemical Characterization and Cell Survival under Submergence, Oxidative and Nitrosative Stress Conditions. Mol. Breed. 2006, 17, 201-216. [CrossRef]

82. Pendse, G.J.; Bailey, J.E. Effect of Vitreoscilla hemoglobin expression on growth and specific tissue plasminogen activator productivity in recombinant Chinese hamster ovary cells. Biotechnol. Bioeng. 1994, 44, 1367-1370. [CrossRef] [PubMed] 
83. Xiong, X.; Xing, J.; Li, X.; Bai, X.; Li, W.; Li, Y.; Liu, H. Enhancement of biodesulfurization in two-liquid systems by heterogeneous expression of Vitreoscilla hemoglobin. Appl. Environ. Microbiol. 2007, 73, 2394-2397. [CrossRef] [PubMed]

84. Martínez, I.; Mohamed, M.E.-S.; Rozas, D.; García, J.L.; Díaz, E. Engineering synthetic bacterial consortia for enhanced desulfurization and revalorization of oil sulfur compounds. Metab. Eng. 2016, 35, 46-54. [CrossRef] [PubMed]

85. Gong, T.; Liu, R.; Zuo, Z.; Che, Y.; Yu, H.; Song, C.; Yang, C. Metabolic engineering of Pseudomonas putida KT2440 for complete mineralization of methyl parathion and gamma-hexachlorocyclohexane. ACS. Synth. Biol. 2016, 5, 434-442. [CrossRef] [PubMed]

86. Gong, T.; Xu, X.; Che, Y.; Liu, R.; Gao, W.; Zhao, F.; Yu, H.; Liang, J.; Xu, P.; Song, C.; et al. Combinatorial metabolic engineering of Pseudomonas putida KT2440 for efficient mineralization of 1,2,3-trichloropropane. Sci. Rep. 2017, 7, 7064. [CrossRef]

87. Gong, T.; Xu, X.; Dang, Y.; Kong, A.; Wu, Y.; Liang, P.; Wang, S.; Yu, H.; Xu, P.; Yang, C. An engineered Pseudomonas putida can simultaneously degrade organophosphates, pyrethroids and carbamates. Sci. Total. Environ. 2018, 628-629, 1258-1265. [CrossRef]

88. Urgun-Demirtas, M.; Stark, B.C.; Pagilla, K.R. Comparison of 2-chlorobenzoic acid biodegradation in a membrane bioreactor by B. cepacia and B. cepacia bearing the bacterial hemoglobin gene. Water Res. 2006, 40, 3123-3130. [CrossRef]

89. Kunkel, S.A.; Pagilla, K.; Stark, B.C. Directed evolution to produce sludge communities with improved oxygen uptake abilities. Appl. Microbiol. Biotechnol. 2015, 99, 10725-10734. [CrossRef]

90. Kahraman, H.; Geckil, H. Degradation of Benzene, Toluene and Xylene by Pseudomonas aeruginosa Engineered with the Vitreoscilla Hemoglobin Gene. Eng. Life Sci. 2005, 5, 363-368. [CrossRef]

91. Khleifat, K.M.; Abboud, M.M.; Al-Mustafa, A.H. Effect of Vitreoscilla hemoglobin gene (vgb) and metabolic inhibitors on cadmium uptake by the heterologous host Enterobacter aerogenes. Process. Biochem. 2006, 41, 930-934. [CrossRef]

92. Harnois, T.; Rousselot, M.; Rogniaux, H.; Zal, F. High-level Production of Recombinant Arenicola marina Globin Chains in Escherichia coli: A New Generation of Blood Substitute. Artif. Cells Blood Substit. Biotechnol. 2009, 37, 106-116. [CrossRef]

93. Liu, L.; Martínez, J.L.; Liu, Z.; Petranovic, D.; Nielsen, J. Balanced globin protein expression and heme biosynthesis improve production of human hemoglobin in Saccharomyces cerevisiae. Metab. Eng. 2014, 21, 9-16. [CrossRef] [PubMed]

94. Ginzburg, Y.Z.; Rybicki, A.C.; Suzuka, S.M.; Hall, C.B.; Breuer, W.; Cabantchik, Z.I.; Bouhassira, E.E.; Fabry, M.E.; Nagel, R.L. Exogenous iron increases hemoglobin in beta-thalassemic mice. Exp. Hematol. 2009, 37, 172-183. [CrossRef] [PubMed]

95. Shen, Q.; Yu, Z.; Zhou, X.-T.; Zhang, S.-J.; Zou, S.-P.; Xiong, N.; Xue, Y.-P.; Liu, Z.-Q.; Zheng, Y.-G. Identification of a novel promoter for driving antibiotic-resistant genes to reduce the metabolic burden during protein expression and effectively select multiple integrations in Pichia Pastoris. Appl. Microbiol. Biotechnol. 2021, 105, 3211-3223. [CrossRef] [PubMed]

96. Malakar, P.; Venkatesh, K.V. Effect of substrate and IPTG concentrations on the burden to growth of Escherichia coli on glycerol due to the expression of Lac proteins. Appl. Microbiol. Biotechnol. 2012, 93, 2543-2549. [CrossRef] 